\title{
Exergames na Educação Física Escolar como potencializadores da ação docente na cultura digital ${ }^{1}$
}

\section{Exergames in the School Physical Education as intensifier of the teaching action in the digital culture}

\author{
Marcio Roberto de Lima* \\ Diego Sousa Mendes* \\ Eduardo de Matos Lima*
}

\begin{abstract}
RESUMO
Este artigo relata a aproximação de uma escola pública urbana dos exergames (EXG) nas aulas de Educação Física Escolar (EFE). A pesquisa objetivou identificar significados atribuídos por um professor ao uso de EXG em sua prática pedagógica e sistematizar potencialidades e limitações da aproximação EXG-EFE. Foram utilizados dois videogames Xbox One com Kinect e contouse com a colaboração de um professor de EFE e de seus alunos do $3^{\circ}$ ano do ensino médio. O estudo caracterizou uma Pesquisa-Ação tendo como base a introdução dos EXG nas aulas, o que permitiu: imersão de pesquisadores no contexto de estudo e suas aproximações dos sujeitos de pesquisa; intervenção no cotidiano escolar; realização de observações; geração de dados empíricos pela via da documentação audiovisual, questionários e entrevista. Em campo, foi possível constatar: reconfiguração dos espaços escolares para a EFE; ressignificações nas ações pedagógicas envolvendo um processo de revisão e reflexão sobre a prática; introdução de novos conteúdos de referência na unidade curricular; melhorias na motivação discente; desenvolvimento
\end{abstract}

1 O presente artigo é um recorte da pesquisa intitulada "Uso pedagógico de exergames como potencializadores da cultura digital escolar e da motivação discente", financiada pela Fundação de Amparo à Pesquisa do Estado de Minas Gerais (FAPEMIG) - Edital Universal n ${ }^{\circ}$ 01/2016 (Processo $\mathrm{n}^{\text {o: }}$ CHE - APQ-02192-16).

${ }^{*}$ Universidade Federal de São João del-Rei. São João del-Rei, Minas Gerais, Brasil. E-mail: marcinholima@ufsj.edu.br - http://orcid.org/0000-0003-3790-1104 E-mail: diegomendes@ufsj. edu.br - https://orcid.org/0000-0002-2297-5883 E-mail: eduardo.henrique@ufsj.edu.br - https:// orcid.org/0000-0002-3467-7760 
de uma cultura participativa discente. As limitações envolvendo o uso pedagógico dos EXG foram associadas ao número de alunos e ao tempo previsto para as aulas. Os indicadores sistematizados na pesquisa sugerem que os EXG propiciam um encontro positivo entre a escola, as práticas da EFE e a cultura digital, podendo essa tecnologia ser considerada como uma expansão das vivências corporais na unidade curricular.

Palavras-chave: Exergames. Educação Física Escolar. Cultura Digital.

\begin{abstract}
This article reports the introduction of exergames (EXG) in the routine of an urban public school in Physical Education (PE) classes. The research sought to understand and systematize teaching meanings about the use of EXG in pedagogical practices, considering potentialities and limitations. In the study two video games Xbox One with Kinect were used by a professor of PE and his students of the 3rd year of High School. Methodologically, an action-research was carried out based on the introduction of video games in the classes, which allowed: immersion of researchers in the context of study and their approximations of the research subjects; intervention in school daily life; generation of empirical data through audiovisual documentation, observations, questionnaires and interview. With these actions it was possible to identify / observe: reconfiguration of school spaces for PE; re-significations in the pedagogical actions involving a process of review and reflection on the practice; introduction of new reference contents in the curricular unit; improvements in student motivation for classes; development of a participatory student culture. The limitations involving the use of EXG in classes were associated with the number of students and the estimated time for classes. The systematized indicators suggest that EXG foster a positive encounter between school, practices of PE and the digital culture, and this technology can be considered as an expansion of the corporal experiences.
\end{abstract}

Keywords: Exergames. Physical School Education. Digital Culture.

\title{
Introdução
}

O contexto contemporâneo revela uma sociedade que tem seus processos mediados com as Tecnologias Digitais de Informação e Comunicação (TDIC). Notadamente, todas as áreas de conhecimento passaram a instrumentalizar projetos e formas de interação com a esfera social pela via virtual, expandindo tempos e espaços de atuação. 
O que se percebe é a consolidação de uma sociedade informacional, que, a cada ciclo de evolução das TDIC, vem se apropriando das funcionalidades dessas tecnologias e reconfigurando as formas de trabalho, lazer e convívio social (SILVEIRA, 2017). Esse movimento criativo e de potencialização da ação humana em ambientes virtualizados revela um novo modus operandi social ora denominado de cultura digital (LEMOS; LÉVY, 2010; LEMOS, 2020). Assim, para além da utilização de artefatos digitais, a cultura digital implica essencialmente - modificação de comportamentos, o que transforma o modus vivendi e reconfigura as ações dos indivíduos, das instituições e da sociedade (LIMA, 2015).

Ambientados no contexto da cultura digital, a educação e seus processos de formação precisam se integrar a essa dinâmica, mostrando-se incluídos e promovendo inclusão nesse "[...] processo de transformação humana [... o que não significa a] substituição de métodos, modalidades e técnicas. Trata-se da criação de espaços para o encontro dos homens mediatizados pelo mundo e pelos instrumentos criados pelo homem [...]" (ALMEIDA, 2004, p. 28). Nesse aspecto, compreende-se que as TDIC são uma dimensão da cultura e que o ambiente educacional é propício para sua integração aos processos educacionais de maneira a (re)adequar a intencionalidade pedagógica às exigências do contexto contemporâneo (CARVALHO; LIMA, 2019).

Nesse cenário, a pesquisa aqui relatada foi proposta e implementada em uma escola pública da cidade de São João del-Rei/MG e contou com a colaboração de um professor de Educação Física e de seus alunos do $3^{\circ}$ ano do ensino médio. A escolha da escola justificou-se pelo bom acolhimento do projeto por seus gestores, pela estrutura assegurada ao projeto, pelas condições de guarda e segurança dos equipamentos envolvidos e, fundamentalmente, pelo interesse, disponibilidade e adesão voluntária de seus professores.

As ações de pesquisa envolveram exergames (EXG), que são jogos eletrônicos, os quais convertem a movimentação corporal real para um "[...] ambiente virtual, permitindo que os usuários [...] pratiquem esportes virtuais, exercícios de fitness e/ou outras atividades físicas [...]" (MEDEIROS et al., 2017, p. 465). Distintos dos jogos eletrônicos tradicionais - que, por vezes, são tipificados como atividades sedentárias (CUSTÓDIO et al., 2019) -, os EXG possuem narrativas fundadas na cultura corporal de movimento e simulam atividades que exigem motricidade (esporte, dança, ginástica etc.), as quais integram temas curriculares da Educação Física Escolar (BETTI, 2001; VAGHETTI; VIEIRA; BOTELHO, 2016). Não obstante, constatamos que as pesquisas e experiências pedagógicas com os EXG na Educação Física vêm aumentando nos últimos anos e os resultados relatados são positivos (BITTENCOURT et al., 2018; GONÇALVES; SANTOS; MOTA, 2018; NUNES; TOIGO; FLORENTINO, 2019). 
Nesse sentido, o estudo aqui sintetizado assumiu como objetivo identificar aspectos emergentes de uma experiência do uso de EXG na Educação Física Escolar, elencando significados atribuídos pelo professor ao uso desses games em sua prática pedagógica. A partir desse objetivo, buscamos sistematizar potencialidades e limitações da aproximação EXG-EFE, verificando se a utilização dessa tecnologia em um contexto de ensino poderia impulsionar a cultura digital escolar.

\section{A pesquisa e seus materiais, método e procedimentos}

A pesquisa empreendida promoveu uma aproximação de uma escola pública urbana dos EXG nas aulas de Educação Física e assumiu essas tecnologias como desencadeadoras de uma relação mais intensa entre tal componente curricular e a cultura digital. Para tanto, foram utilizados dois videogames Xbox One com sensores Kinect ${ }^{2}$, da empresa Microsoft ${ }^{\circledR}$, e dois televisores LED de 55 polegadas.

É indispensável sinalizar que, ao envolver a unidade curricular da EFE e suas práticas, não negligenciamos que os jogos eletrônicos tradicionais foram/são tratados sob o prisma de favorecer a inatividade física/obesidade dos jogadores (HEDLEY et al., 2004). Sob outro prisma, assumimos o aprimoramento dos videogames com EXG como uma forma de provocar uma ruptura com tal paradigma. Neste estudo, a virtualização foi tratada como uma possibilidade potencializadora de novas formas de se pensarem as práticas da EFE, indo ao encontro de uma reconfiguração da cultura corporal de movimento na cultura digital.

O trabalho desenvolvido foi de natureza qualitativa (LÜDKE; ANDRÉ, 1986) e configurou-se como uma Pesquisa-Ação (STENHOUSE, 1993; THIOLLENT, 1996). A experiência de intervenção escolar foi elaborada e desenvolvida em parceria com um professor colaborador da escola, um bolsista de iniciação científica, uma bolsista de mestrado e dois professores orientadores da Universidade Federal de São João del-Rei (UFSJ).

Os dados empíricos foram gerados por intermédio de: registros em diário de campo de todas as aulas e atividades realizadas durante o período da pesquisa; fotografias das práticas empreendidas; realização de uma entrevista

2 Os sensores Kinect são capazes de captar com boa margem de exatidão e desenvoltura os movimentos corporais do jogador, reproduzindo-os no ambiente de interação dos games. 
semiestruturada com o professor participante do estudo. A entrevista foi registrada em gravação digital de áudio, teve a duração aproximada de uma hora e foi realizada nas dependências da UFSJ em horário agendado pelo colaborador. Após sua realização, seu conteúdo foi inteiramente transcrito e, junto com os demais dados empíricos, passou por um tratamento qualitativo com o uso de ferramentas da Análise Categorial Temática (BARDIN, 2016). Esse processo ${ }^{3}$ foi estruturado no software Atlas.ti, que nos auxiliou no tratamento, relacionamento e inferências dos/com os dados.

A fase exploratória da Pesquisa-Ação iniciou-se em novembro de 2017 quando foi realizado um contato com um professor de Educação Física para convidá-lo a trabalhar com os EXG em suas futuras aulas. O professor $\mathrm{Charles}^{4}$ aceitou nossa proposta e se integrou à nossa equipe. $\mathrm{O}$ passo subsequente envolveu o planejamento das ações de pesquisa e intervenção na escola, as quais foram concebidas conjuntamente com Charles. Nessa etapa, solicitamos ao docente que propusesse um EXG que poderia ser interessante para suas aulas, tendo sido escolhido o pacote Kinect Sports Rivals.

A etapa de intervenção no espaço escolar foi realizada entre os meses de março e abril de 2018. Naquele período, foi colocado em ação um plano de ensino, que totalizou 14 aulas consecutivas, junto a duas turmas de terceiros anos do ensino médio. A estratégia de intervenção contemplou a apresentação formal do conteúdo "tênis" (uma aula), apresentação do projeto com os EXG (uma aula), prática da modalidade tênis e suas variações (dez aulas) e avaliação (duas aulas). Nas intervenções nas aulas, foram utilizados materiais tradicionais do tênis (raquetes e bolas de tênis) e, também, o jogo virtual de tênis.

A estrutura das aulas com os EXG foi pensada para que todos os alunos pudessem usufruir da experiência e a estratégia adotada foi a da divisão da turma em oito grupos de cinco alunos (que também fariam a avaliação em conjunto em forma de apresentação de trabalho). Como o projeto só dispunha de dois consoles, os oito grupos se alternavam entre aulas concomitantes nas quadras e nos espaços com EXG - a saber, o anfiteatro e a biblioteca da Escola $X^{5}$. Assim, em uma mesma aula, quatro grupos usufruíam dos EXG (dois grupos por ambiente, alternando-se ao longo da aula), enquanto os demais grupos estavam

3 Registramos que todas as etapas metodológicas previstas em Bardin (2016) foram realizadas no ambiente do Atlas.ti e, sinteticamente, envolveram: pré-análise, codificação, definição de categorias temáticas e realização de inferências analíticas. A discussão analítica dos dados é apresentada em seção própria neste artigo.

4 A fim de preservar a identidade do professor colaborador deste estudo, adotamos ficticiamente o nome Charles, conforme registrado no Termo de Consentimento Livre e Esclarecido (TCLE) assinado pelo docente.

5 Nome fictício adotado para a escola onde foi realizada a pesquisa. 
nas quadras. $\mathrm{Na}$ aula posterior, os alunos eram invertidos nos espaços, ou seja: quem já havia experimentado os EXG iria para a quadra, e vice-versa. Todos os grupos puderam experimentar as práticas virtualizadas pelo menos por duas vezes (aulas de 50 minutos). Esse arranjo didático foi facilitado pela presença da equipe de pesquisadores junto com o professor e permitiu um acompanhamento de todos os espaços por parte dos envolvidos na Pesquisa-Ação.

\section{Apresentação e discussão analítica dos dados}

Considerando nossos objetivos de pesquisa, os dados gerados na entrevista decorreram de questões norteadoras, as quais originaram as categorias analíticas apresentadas no Quadro 1:

\section{QUADRO 1 - QUESTÕES DE PESQUISA E CATEGORIAS ANALÍTICAS}

\begin{tabular}{|l|l|}
\hline Questões norteadoras & Categoria analítica \\
\hline $\begin{array}{l}\text { O que emerge da experiência do uso de exergames } \\
\text { na educação física escolar? }\end{array}$ & Exergames: aspectos emergentes \\
\hline $\begin{array}{l}\text { Quais os significados atribuídos pelo professor } \\
\text { ao uso dos exergames na educação física escolar? }\end{array}$ & Exergames: significados docentes \\
\hline $\begin{array}{l}\text { Quais as potencialidades educacionais e, ao } \\
\text { mesmo tempo, as limitações dessa aproximação } \\
\text { (exergames-educação física escolar)? }\end{array}$ & Exergames: potencialidades e limitações \\
\hline $\begin{array}{l}\text { Enfim, seriam os exergames uma possibilidade à } \\
\text { educação física escolar e ao fomento da cultura } \\
\text { digital na escola na visão do professor? }\end{array}$ & $\begin{array}{l}\text { Exergames: possibilidade à EFE e fomento à } \\
\text { cultura digital escolar }\end{array}$ \\
\hline
\end{tabular}

FONTE: Elaborado pelos autores.

\section{Exergames: aspectos emergentes}

O primeiro aspecto que despertou nossa atenção diz respeito ao ineditismo do uso dos EXG nas práticas de EFE na Escola X. Charles afirmou que nunca havia experimentado esse tipo de aproximação em suas aulas e que sequer tinha conhecimento daquela modalidade de jogos. E, ampliando o contexto daquela novidade, indicou a reação dos gestores e dos outros colegas, avaliando positivamente a oportunidade: 
[...] deu uma sacudida na escola, né? Em termos da Direção... E outro sobre os outros professores observarem aquilo, né? Muitos iam passando ali pela biblioteca (um dos locais que foi disponibilizado para a prática com os EXG) e alguns chegavam na sala dos professores: '- Nó! Que doideira! Que legal! Que massa! [...] Que bacana! Que que é isso?' [...] Esse foi [um] ponto positivo... que a escola observar que é possivel, né? (Prof. Charles).

Na ocasião, os videogames - atípicos no contexto escolar - possibilitaram uma aproximação da escola e de seus sujeitos a uma nova forma de se pensar as práticas pedagógicas e a representação da Educação Física na cultura escolar. Segundo Mendes (2016), o "algo novo" presente na rotina escolar, citado pelo professor, é capaz de mudar condutas e hábitos docentes por gerar "efeito de surpresa, de espanto e admiração". Isso poderia provocar novas representações e mesmo rompimento com associações, esquemas ou ideias já previamente cristalizadas na cultura docente. Por sua vez, isso sugeriria novas associações imagéticas mobilizadoras para a modificação de comportamentos. Assim, a adaptação no fazer pedagógico docente trouxe implicações no planejamento e desenvolvimento das aulas, emergindo, por exemplo:

A questão do tempo, das diferenças de um ano para o outro, né? Esse ano eu tive que lançar mão de mais tempo [...] em relação ao ano passado. Nós ficamos basicamente um bimestre com tênis, né? No ano passado, não... foi um mês de tênis (Prof. Charles).

O excerto anterior sugere que uma adaptação no campo de ação do professor com o uso de uma tecnologia digital irá, também, ressignificar o tempo de duração do desenvolvimento da unidade didática planejada inicialmente pelo professor, já que, na escola em que foi realizada a pesquisa, não era possível alterar um tempo de duração das aulas (50 minutos) - o que se mostrou como uma demanda potencial. A utilização pedagógica dos EXG nas aulas de EFE implicou divisão da turma de alunos e alternância entre grupos discentes em práticas de quadra e com o jogo virtual. Isso requereu tempo e não implicou, necessariamente, perda de tempo. Não se pretendia um rompimento excludente entre as práticas pedagógicas já realizadas pelo professor e as com EXG, mas um (re)alinhamento inovador com vistas ao ganho de aprendizagem e revisão da docência. Afinal, 
[...] não se trata aqui de usar a tecnologia a qualquer custo, mas sim de acompanhar consciente e deliberadamente uma mudança de civilização que questiona profundamente as formas institucionais, as mentalidades e a cultura dos sistemas educacionais tradicionais e sobretudo os papéis de professor e aluno (LÉVY, 1999, p. 172).

Ainda envolvendo as modificações da esfera pedagógica, as práticas alternadas entre os EXG e as de quadra evidenciaram reposicionamento nas relações entre o professor e os alunos. Por envolver divisão de grupos em espaços distintos e em tempos simultâneos, as experiências fomentaram uma horizontalização nas interações pedagógicas:

[...] Então, assim, o videogame proporcionou isso também [...]. No caso nem foi uma igualdade, porque acabou que inverteu o papel, né? Eles começaram a me ensinar as questões (dos EXG) [...] os meninos, uma parte, eles têm acesso a isso, então [...] eles me ajudaram (Prof. Charles).

A dinâmica narrada por Charles evidencia troca de saberes, partilha de experiências e construção coletiva (MASETTO, 2012) entre o docente e seus alunos, que, em outros estudos relativos ao uso das mídias e TDIC no âmbito da EFE, também foram constatadas (MENDES, 2008; MENDES, 2016; MENDES; BETTI, 2018). A valorização do conhecimento prévio dos alunos pelo professor favorece o envolvimento discente, além de reconfigurar a relação entre "quem ensina e quem aprende". Nessa perspectiva, emerge uma melhor contextualização dos conteúdos de referência, o que altera significativamente a aprendizagem e o próprio processo de ensino.

\section{Exergames: significações docentes}

Um primeiro aspecto a ser destacado é a associação da tecnologia introduzida nas aulas com a cultura digital: "O próprio videogame é um encontro com a cultura digital, [...] a gente já tem isso bem marcado" (Prof. Charles). A relação feita pelo docente ressalta o pensamento de que os artefatos digitais assumem um lugar de destaque no atual contexto sociocultural. Portanto, os 
videogames seriam - tal como os computadores, smartphones, tablets etc. ícones culturais. Evitamos, aqui, interpretar uma visão determinística sobre as tecnologias digitais, compreendendo que os seus usos e apropriações implicam a modificação de comportamentos, o que transforma a cultura e reconfigura as ações dos indivíduos, dos grupos e da sociedade (LIMA, 2015).

O princípio da reconfiguração de ações como pressuposto da cultura digital, conforme entendimento de Lemos e Lévy (2010), assumiu uma significação para Charles que, ao aderir à experiência com os EXG em seu fazer pedagógico, nos participou que teve de

[...] investir em conhecer, né? O que é o Xbox? Né? Em casa, eu tive que ir procurar, quando vocês falaram dos nomes [dos exergames e do videogame] lá, esse tipo de investimento. [...] porque, quando vocês falaram disso, eu já comecei a imaginar o que que seria possivel ou não. Nas férias mesmo, eu já ficava meio assim: '- Será o que que dá para fazer?' (Prof. Charles).

Entendendo que a oportunidade de trabalhar com o esporte virtualizado com os EXG não recaiu na mera substituição de práticas tradicionais; notamos na fala do professor um início de um processo de reflexão sobre suas ações, o que significa quebra de rotina e o redesenho de futuras ações pedagógicas (ZEICHNER, 1993). As possibilidades associadas ao uso dos EXG nas aulas de EFE passaram a configurar-se no planejamento pedagógico de Charles e, possivelmente, inspiraram nele novas ideias. Esse aspecto vai ao encontro do movimento de renovação de ações interposto pela cultura digital e suas velozes transformações, as quais impõem um novo ritmo à tarefa de ensinar e aprender (KENSKI, 2003).

Ainda nesse contexto, o professor considerou os EXG como uma alternativa para a expansão da cultura corporal do movimento e para provocar discussões, sendo os videogames identificados como relevantes às aulas de EFE:

[...] jet ski... só dá para ter a prática do jet ski (nas aulas de EFE) como Xbox. Então, é uma forma de ampliar essa experiência corporal deles. E aí-é óbvio, né? - discutir como é essa experiência... Que não é na relação com o mar, com a máquina (jet ski) e o mar... Mas é uma outra relação, né? Essa relação TV-corpo simulado. Então, acho que isso é um ganho muito bom, muito bom, assim, para a Educação Física (Prof. Charles). 
Estabelecendo um sentido pedagógico para os EXG, o professor problematiza a virtualização do corpo como uma abordagem geradora de questões a serem trabalhadas com seus alunos. Notadamente, o atual é potencializado pelo virtual, que, no caso específico, expande a experiência corporal nas aulas de EFE com a experiência do jet ski (LÉVY, 1996). Ou seja, em sua aproximação com a EFE, os EXG podem ser compreendidos como "[...] uma possibilidade de direcionar para o surgimento de novos modos de cognição e de percepção" (VAGHETTI; VIEIRA; BOTELHO, 2016, p. 14).

Um último significado docente identificado junto ao professor Charles está relacionado à dupla exposição que um EXG, inevitavelmente, propicia. Pensar o movimento virtualizado remonta sua relação com o movimento no atual (LÉVY, 1996). Dessa forma, o corpo virtualizado no exergame irá reproduzir, com boa margem de precisão, a partir de uma dinâmica originada pelo movimento do corpo físico, outro movimento virtualizado correspondente ao gesto motor de algum modelo idealizado ou espetacularizado. Disso, decorre uma ambiguidade que se traduziu: ora em potencial mobilizador para os estudantes, dado que aqueles alunos que não tinham uma técnica ainda apurada de determinada prática corporal, bastando fazer algum gesto aproximado, ou que em princípio tivesse alguma correlação mimética simplificada com o movimento técnico especializado simulado no game, poderia conseguir executá-los virtualmente; ora como limitador da experiência corporal por evidenciar dificuldades motoras ou de exposição corporal de alguns estudantes e do professor Charles de forma pública.

Em um EXG com a temática da dança, em que os movimentos de um avatar são pontuados em sincronia ao sequenciamento de passos rítmicos realizados pelo jogador, caso este não seja capaz de acompanhar a dinâmica proposta pelo jogo, sua falta de técnica fica duplamente evidenciada: na tela do jogo e no espaço tradicional de lugar. Ao comentar um possível trabalho com dança a partir desse jogo, o docente expressou constrangimento:

Na quadra, modéstia à parte, eu vou bem, mas dançar [...] acho que meu problema é, assim... Vai ser, assim... Os olhares, assim, né? Acho que vai me constranger um pouco [...] me olhar fazendo movimento de furar ou um Forehand (golpe do tênis) não tem problema nenhum! Agora, fazer [...] o que seja um passo bom, eu acho que eu vou ter problema (Prof. Charles).

O professor, que aparentou não ter um domínio da dança, manifestou acanhamento com erros em uma possível prática virtualizada. Assim, o EXG (na 
modalidade de dança) assumiu um lugar de gerar constrangimento mediante a dupla exposição de falta de técnica. Entretanto, é importante considerar que os erros evidenciados durante uma prática em um exergame também representam chances para uma melhor percepção corporal, o que pode levar ao aperfeiçoamento do controle motor e competências de seus jogadores no que se refere às capacidades físicas exigidas dos jogadores diante da tela, mas não necessariamente daquelas exigidas pelas práticas corporais tematizadas nos games quando em contextos não virtualizados (DALEY, 2010).

Portanto, evidenciou-se que o mecanismo de simulacro presente no EXG tanto poderia ser lido criticamente como empobrecedor da experiência, no sentido proposto por Benjamin (1992), pois se tratava de uma vivência simplificada e simplificadora do que seja a dinâmica da prática corporal em contextos não virtualizados, mas também dispunha aos estudantes uma possibilidade de reprodutibilidade técnica daqueles movimentos, que lhes convidava a produzir significações a respeito delas, ora sendo elemento de distanciamento dos sujeitos da pesquisa em relação à proposta de movimentação instada no modelo virtualizado, ora sendo aspecto motivador para exposição corporal, promoção da ludicidade e engajamento de muitos estudantes com as situações de motricidade e as reflexões proporcionadas nas aulas.

\section{Exergames: potencialidades e limitações}

No que diz respeito às "potencialidades" dos EXG, um primeiro aspecto identificado junto ao professor colaborador deste estudo foi a ampliação de seu campo de ação pedagógica:

Outra coisa que enriquece é a possibilidade de ter contato com determinadas práticas em que o material ainda não chegou à escola, né? Por exemplo, no $2^{\circ}$ ano, eu trabalho no $4^{\circ}$ bimestre com práticas corporais de aventura e, em 2016, eu fiz um oficio pedindo uma parede de escalada para o Exército e eu não tive resposta. Esse ano, tem o Xbox, TV lá, né? Escalada vai entrar no planejamento, né? [...] Só vai ter escalada, porque tenho Xbox (Prof. Charles).

O discurso do docente sugestiona que o campo da ação pedagógica é expandido com os EXG, os quais simulam atividades esportivas atípicas ao 
ambiente escolar. Acreditamos que essa aproximação (EXG-EFE) pode conduzir a um movimento criativo de se (re)pensar o "fazer" pedagógico, substanciando as formas de atuação dos professores. Essa constatação se aproxima das evidências que Vaghetti et al. (2018, p. 79) destacam em seu estudo, no qual ficou constatado que os EXG podem ser considerados "uma estratégia metodológica de diversificação da intervenção em Educação Física Escolar". Entendemos, também, que a presença do videogame nas aulas de EFE é um fator que condiciona as eventuais ressignificações, isso quando utilizado de maneira a estimular motricidade, reflexão, criatividade, diálogo, cognição e o campo afetivo dos sujeitos envolvidos.

Do ponto de vista do ensino, Charles nos indicou a eficácia de um EXG para contextualizar, problematizar e experimentar um determinado conteúdo de referência. Nessa ótica, o professor admitiu que sua "[...] tentativa de fala e disposição de regras não foi tão eficaz quanto a linguagem do digital ali, que, né?!, toda hora aparecia 15-00 / 15-15 / 30-15 / Game (pontuação do tênis), né?" e que, com os EXG, os alunos "[...] perguntavam também no ato, né?" (Prof. Charles). De certa forma, o que aconteceu foi uma reconfiguração na forma de ensino tradicional: um conteúdo, que normalmente partia da exposição, foi vivenciado virtualmente, gerando dúvidas e caminhos de significação pessoal para os alunos. Ou seja: a regra de pontuação do tênis assumiu sentido para os discentes a partir da experiência virtualizada, ainda que trabalhada previamente em um momento de exposição em sala de aula.

Ampliando essa linha de raciocínio, a incorporação dos EXG ao planejamento de Charles introduziu uma nova linha de problematização junto aos alunos, o corpo virtualizado: “[...] a gente vivenciou o real e o virtual, né? Então, assim, é um ganho muito significativo. Assim, de poder vivenciar isso e pensar sobre isso, né? Ser afetado por essas formas... Alguns já têm esse cotidiano, outros não" (Prof. Charles). Podemos notar que, da utilização dos EXG nas aulas de EFE, emergem novos campos de significação do movimento e do próprio corpo. Dessa forma, se o mundo é aquilo que se vive (MERLEAU-PONTY, 1997), a experiência da virtualização do corpo implica integração dinâmica de diferentes modalidades perceptivas, promovendo reconstruções (LÉVY, 1996).

A partir dos indícios anteriores, identificamos, também, que os EXG podem fomentar um maior envolvimento discente na proposta pedagógica em curso conforme sugerido pelo professor ao comentar o momento de avaliação:

[...] o que me surpreendeu muito foi a produção deles [...] Eles têm os problemas com data, porque é muita coisa acumulada. Os alunos perguntando: '- Ah, é para amanhã?'' (o trabalho avaliativo). Então, até 
falei para ele (um pesquisador da equipe) assim, ó: '-Não espera muita coisa, não!' (dos trabalhos dos discentes). Fiquei meio com medo, mas foi o contrário, né? Muito cuidado, coisas ricas, né? [...] e eu fiquei bem surpreso, assim, e satisfeito com o desenvolvimento deles (Prof. Charles).

Conforme explicitado na seção de descrição da pesquisa e seu método, a intervenção com os EXG dispôs de um momento de avaliação discente. Charles chama a atenção para a deficitária organização do tempo pelos alunos, que deixam acumular tarefas do cotidiano escolar. Esse fator foi gerador de dupla carga afetiva no professor: desconfiança/apreensão e, ao final, surpresa/ satisfação. Embora o escopo deste trabalho se dirija às significações docentes sobre nossa intervenção nas aulas, cabe registrar que os alunos fizeram trabalhos que expunham seus aprendizados acerca da modalidade praticada, expressavam sentidos à experiência vivenciada, estabeleciam contraposições entre o tênis jogado na quadra e no espaço virtualizado, além de integrarem aspectos pertinentes à cultura digital. Ao final, os trabalhos apresentados pelos alunos sugeriam ao professor um envolvimento diferente do usual, surpreendendo-o.

Quanto às limitações (pontos negativos) atribuídas ao uso dos EXG nas aulas de EFE, destacamos o "corre-corre da escola" (Prof. Charles). Unido ao excessivo número de alunos por turma (média de 40), o tempo para organizar e experimentar as atividades planejadas foi um fator que merece atenção. Compreendemos que o horário das aulas com os EXG precisaria ser superior aos 50 minutos, favorecendo as experiências entre as práticas virtualizadas e as que envolviam a quadra esportiva. Com esse indicativo, notamos que o número de videogames e Smart TVs precisariam ser ampliados para quatro pares (foram utilizados dois pares), o que poderia conferir dinamismo ao trabalho entre grupos de alunos.

Do ponto de vista pedagógico, Charles não se furtou de indicar que os EXG podem potencializar a chamada "pedagogia da sombra", ou seja: propostas, cuja pretensão não transcende a ocupação do tempo da EFE com alguma atividade, que, por vezes, acaba por servir de recreação para os alunos ou como compensação do tédio no espaço escolar (SILVA; BRACHT, 2012). Nessa concepção, a qual é de responsabilidade individual de um docente, o videogame - como qualquer outro material didático - pode se configurar como um dispositivo, cuja utilização é infrutífera para a promoção de problematizações e para a (re) construção do aprendizado. 


\section{Exergames: possibilidade para a EFE e fomento à cultura digital escolar}

Após o término de nossas interações com as turmas de Charles, o professor pôde refletir e avaliar o projeto implementado. A partir de sua experiência didática com os videogames e dos resultados observados com os seus alunos, questionamos o professor se ele considerava a integração dos EXG como uma possibilidade à EFE:

Totalmente. Eu não encaro para política pública. Eu acho que eles (governo) não têm essa noção. Eles não têm noção da importância disso para a escola, para a Educação Física, para as outras disciplinas. Mas para a Educação Física, enquanto disciplina do currículo escolar, sem dúvidas. Com essa experiência então... Porque, eu também ficava muito nessa questão da literatura dos jogos virtuais, tal... '- Nossa, será que tem jeito mesmo?' Aí, eu sempre, assim: '- Nossa cara, a galera está fazendo lá em São Paulo, estudar isso...' [...] videogame, lá, na sala... E eu ficava desesperado vendo as fotos dos artigos e os meninos... '- Meu Deus do céu, será que dá? 'Aí, deu! Então, assim, para a Educação Física escolar, totalmente (Prof. Charles).

O excerto discursivo do docente destacou - em dois momentos - os EXG como uma contribuição à ação pedagógica nas aulas de EFE. Com o projeto desenvolvido na Escola X, o que era acessado por Charles somente a partir das discussões da literatura encontrou um lugar em suas ações didáticas: os videogames e os EXG passaram a integrar o cotidiano das suas aulas, foram significativos às interações pedagógicas e, portanto, se constituíram como um recurso relevante. Ainda em seu posicionamento, o docente indica que não identificava ações no âmbito da política pública educacional, as quais poderiam introduzir esse tipo de formação profissional e os videogames/EXG como recurso didático no contexto escolar.

Em um segundo momento, introduzimos as questões pertinentes ao fomento da cultura digital no cotidiano escolar pela via dos EXG. Nesse particular, em um momento inicial de nosso diálogo, Charles expressou

[...] que a cultura digital, ela acontece. Vamos ter lá, agora, 43 computadores novos. Tá para chegar. Já fiquei sabendo disso terça-feira [...]. É fone de ouvido: têm caixas; microfones: têm caixas. Vai ter um curso agora da lousa digital. Então, cultura digital tem chegado, tem se investido nisso. 
Notamos, nesse trecho específico, uma perspectiva da cultura digital escolar ligada diretamente ao aparelhamento dos ambientes de ensino. Dispor infraestrutura para o trabalho com tecnologias na escola é condição indispensável - porém, não única - para se pensarem caminhos que assegurem a (re) adequação da intencionalidade pedagógica às exigências da cultura digital (LIMA, 2015). Nessa visão, Charles mostrou-se consciente de que

[...] o investimento maior é na mudança da cultura escolar. Não adianta nada, você tem lá 43 alunos, né? Você pode me dar 20 Xbox. Se eu continuar com 43 alunos: eu tô ferrado, eu tô mal das pernas. Então, tem que mudar a cultura e a estrutura da escola [...]. Colocamos $95 \%$ das escolas com Smart TV. É a política do número: todas as escolas têm data show nas salas. E o professor, ele dá conta de mexer na Smart TV? Ele consegue produzir conteúdo no You Tube para usar a Smart TV? Eu consigo mexer no Xbox? Você vai me dar 20, mas eu consigo? (Prof. Charles).

Destacadas as condições materiais, emerge o impacto cultural vivenciado pelos professores quando eles se depararam com propostas de incorporação de tecnologias digitais às suas práticas. Na fala do docente, o fato aparece relacionado à cultura organizacional escolar, a qual precisaria ser reconfigurada. De fato, o "aparelhar" pode sugerir uma tentativa de se conferir força a uma espécie de determinismo tecnológico, que subverteria a organização e a cultura escolar, sem empecilhos (CASTELLS, 1999). Entretanto, essas transformações não são efetivadas de maneira simplista e/ou por decreto. Não se pode ignorar que estamos diante de um processo historicamente constituído, que envolve valores e tradições no modo de operar o ensino e a própria formação do professor (SANDHOLTZ; RINGSTAFF; DWYER, 1997).

$\mathrm{Na}$ tentativa de se aproximar a escola do contexto da cultura digital, assumimos a formação docente para as tecnologias digitais como prioridade. É indispensável promover o aprofundamento de discussões a respeito do uso crítico dessas tecnologias e dos seus desdobramentos na aprendizagem e, do ponto de vista prático, fomentar uma formação que priorize a elaboração de estratégias de uso contextualizado, individual e coletivo, culminando com a (re) construção de sentidos com/a respeito da tecnologia digital. De outra forma, os recursos digitais podem ser subutilizados, limitando-se ao uso instrumental, ou, até mesmo, serem repelidos (LIMA; NASCIMENTO, 2016). 
Foi nesse aspecto que, na elaboração de nossa proposta de intervenção, consideramos a participação do professor no planejamento das ações pedagógicas, acompanhando-o e colaborando junto com ele nas aulas de EFE com os EXG. Em âmbito geral, ao sistematizar as considerações de Charles, percebemos que nossa Pesquisa-Ação encampou um momento de formação continuada em serviço. E, no sentido de aproximação da escola da cultura digital, o docente nos indicou que o projeto foi "[...] uma forma de a escola se aproximar desse contexto, que é o contexto da cultura digital, que está na sociedade, mas a escola, de certa maneira, está meio que numa redoma" (Prof. Charles).

Logo no início de nossas visitas à Escola X para planejamento, conscientizamo-nos da proibição - na forma da Lei Estadual n 14.486/2002 (MINAS GERAIS, 2002) - do uso de celulares naquele ambiente. Isso porque almejávamos que os discentes pudessem registrar as práticas corporais em forma de fotografias e vídeos, os quais integrariam suas avaliações no formato do trabalho final do projeto. $\mathrm{O}$ conflito entre nossa proposta e a legislação gerou um momento interessante e que propiciou uma reflexão sobre a própria Lei:

[...] nós dois (pesquisador e professor) tivemos que ir à Direção numa reunião, para a gente negociar. Foi uma negociação, fizemos uma negociação, autorização é uma negociação, para que eles pudessem fazer uso de celular com a finalidade pedagógica. Porque a gente sabe que tem uma lei que proíbe uso de celular na escola e o diretor foi muito bacana, com uma posição muito clara: '- Se tem uma finalidade pedagógica, nós não estamos contrariando Lei, de jeito nenhum. Nós estamos fazendo nossa pedagogia com a tecnologia, né?'(Prof. Charles).

Quando descontextualizada, a letra da lei pode reforçar a ideia de uma escola protegida por uma "redoma". Contudo, tal Legislação estabelece, no primeiro parágrafo de seu Artigo $1^{\circ}$, que: "Em salas de aula, bibliotecas e demais espaços destinados ao estudo, é vedado também o uso de outros aparelhos eletrônicos que possam prejudicar a concentração de alunos e professores, salvo em atividades com fins pedagógicos" (MINAS GERAIS, 2002). Assim, a negociação indicada por Charles foi lícita e a gestão escolar não interpôs empecilhos ao bom andamento do projeto. Ao contrário, o que observamos foi um interesse generalizado (dos diretores escolares, dos demais professores, dos secretários, da bibliotecária, dos zeladores, de alguns pais etc.) pelo que estava acontecendo durante as aulas de EFE com os EXG. 


\section{Considerações finais}

Esta pesquisa teve como objetivo principal identificar aspectos emergentes de uma experiência do uso de EXG na EFE, elencando significados atribuídos pelo professor ao uso desses games em sua prática pedagógica.

Por tudo o que foi analisado, pudemos constatar que a incorporação dos EXG no âmbito do currículo praticado pela Educação Física pode desencadear reconfigurações relevantes na atividade docente e mesmo na cultura escolar. Em primeiro lugar, observamos que a chegada dos EXG e, com eles, da cultura digital, na escola incitou mudanças expressivas na forma como o professor utilizava o espaço escolar para suas aulas. Os encontros passaram a ocorrer em três espaços diversos ao mesmo tempo: quadra, biblioteca e anfiteatro. A reconfiguração espacial implicou:

a) Novas formas de organização das turmas, que precisavam se auto-organizar nessas circunstâncias;

b) Menor homogeneização das aulas e das atividades desenvolvidas, posto que, em cada um dos espaços, os estudantes organizavam-se em pequenos grupos, realizando cada qual atividades diversas, porém interligadas e complementares. Enquanto alguns grupos jogavam os EXG na biblioteca ou no anfiteatro, outros filmavam as atividades e havia aqueles que desenvolviam atividades na quadra da escola correlacionadas às temáticas presentes nos EXG vivenciados;

c) Desenvolvimento de estratégias de acompanhamento das turmas mais descentralizadas. Nessa condição, não cabia ao professor ser o único responsável pela aula, pela organização do espaço e das atividades, sendo essa responsabilidade compartilhada com os estudantes e com os pesquisadores atuantes no estudo. Do mesmo modo, o professor passou a transitar entre os diversos ambientes com ações e atividades simultâneas, para nelas mediar as relações educativas que deveriam se interpor e conectar-se.

Portanto, tal como nas relações interativas da cultura digital, foi desencadeada uma inflexão para um modelo de ensino baseado em conexões, em pequenas redes, que permitiram multiplicidade de recorrências: conectividade, diálogo, participação e colaboração.

A aproximação das práticas educativas da EFE à cultura digital por meio dos EXG também implicou, como destacado pelo professor Charles, um aumento de comunicações espontâneas, que emergiram durante a experiência realizada, gerando uma reordenação dos momentos de debates sobre as aulas e o conteúdo. Esse aspecto é relevante, pois, de novas relações comunicativas, nascem novas subjetividades e novas formas de conhecer. 
Apesar de termos clareza de que os resultados obtidos não decorreram meramente de um efeito tecnológico, mas também da capacidade docente qualificada e crítica do professor, da abertura da escola à pesquisa e da presença constante da equipe de pesquisadores nesta empreitada, constatamos que os EXG proporcionaram (inter-)relações relevantes no tocante à reconfiguração nas ações pedagógicas, a qual se mostrou positiva ao professor participante do estudo.

Como limites encontrados na experiência realizada, apontamos que, em pequena escala e fora de uma ação curricular mais transversal e coletiva, a presença dos exergames sozinha não é capaz de afetar a cultura escolar a ponto de proporcionar uma presença mais radical da cultura digital na instituição e mesmo no componente curricular analisado. Já a pesquisa teve limites no que diz respeito ao número de contextos escolares e de turmas analisadas, o que sugere que mais estudos com a temática sejam realizados, em especial em condições escolares e em outras turmas, para que os resultados aqui apontados possam ser mais aprofundados.

Mesmo assim, foi possível confirmar a premissa de que a virtualização e a presença da cultura digital em posse de docentes qualificados pode favorecer a criação de novos ambientes de aprendizagem e potencializar novas maneiras de se construírem conhecimentos na Educação Física Escolar e mesmo em outros componentes curriculares, reconfigurando o campo de ação dos sujeitos envolvidos na esfera educativa.

\section{REFERÊNCIAS}

ALMEIDA, Maria Elizabeth B. de. Inclusão Digital do Professor: formação e prática pedagógica. São Paulo: Articulação, 2004.

BARDIN, Laurence. Análise de conteúdo. São Paulo: Edições 70, 2016.

BENJAMIN, Walter. Sobre arte, técnica, linguagem e política. Lisboa: Relógio D’Água, 1992.

BETTI, Mauro. Educação física e sociologia: novas e velhas questões no contexto brasileiro. In: CARVALHO, Yara M.; RUBIO, Katia. Educação fisicica e ciências humanas. São Paulo: Hucitec, 2001.

BITTENCOURT, Marlom Z. et al. O Potencial dos Exergames para desenvolvimento de Atitude Positiva na Educação Física Escolar. RENOTE-Revista Novas Tecnologias na Educação, Porto Alegre, v. 16, n. 2, p. 190-199, 2018. Disponível em: https://seer. ufrgs.br/renote/article/view/89260/51500. Acesso em: 14 abr. 2020. 
CARVALHO, Daiane A. C.; LIMA, Marcio R. de. Formação de professores para o uso pedagógico das tecnologias digitais de informação e comunicação: uma visão dos marcos legais contextualizada nos cursos da UFSJ. Revista Brasileira de Ensino de Ciência e Tecnologia, Ponta Grossa, v. 12, n. 1, p. 290-313, 2019. Disponível em: https://periodicos. utfpr.edu.br/rbect/article/view/7586/pdf. Acesso em: 9 abr. 2020.

CASTELLS, Manuel. A Sociedade em Rede. São Paulo: Paz e Terra, 1999.

CUSTÓDIO, Iazana G. et al. Uso de exergames em adolescentes: fatores associados e possibilidade de redução do tempo sedentário. Rev. paul. pediatr., São Paulo, v. 37, n. 4, p. 442-449, dez. 2019. Disponível em: http://www.scielo.br/scielo.php?pid=S010305822019000400442\&script=sci_arttext\&tlng=pt. Acesso em: 14 abr. 2020.

DALEY Amanda. Can exergaming contribute to improving physical activity levels and health outcomes in children? Pediatrics, [s.l.], v. 124, n. 2, p. 763-771, 2010.

GONÇALVES, Jane K. R.; SANTOS, Joanan R. dos; MOTA, Priscila S. A. Aproximações entre os exergames e os conteúdos da educação física escolar. Revista Saúde Física \& Mental, Belford Roxo, v. 6, n. 1, p. 74-92, 2018. Disponível em: https://revista.uniabeu. edu.br/index.php/SFM/article/view/3405. Acesso em: 14 abr. 2020.

HEDLEY, Allison et al. Overweight and obesity among US children, adolescents and adults 1999-2002. Jama, [s.l.], v. 291, n. 23, p. 2847-2850, 2004.

KENSKI, Vani M. Tecnologias e Ensino Presencial e a Distância. Campinas: Papirus, 2003.

LEMOS, André. Epistemologia da comunicação, neomaterialismo e cultura digital. Galáxia, São Paulo, n. 43, p. 54-66, abr. 2020. Disponível em: http:/www.scielo.br/pdf/ gal/n43/1982-2553-gal-43-0054.pdf. Acesso em: 9 abr. 2020.

LEMOS, André; LÉVY, Pierre. O futuro da Internet: Em direção a uma ciberdemocracia planetária. São Paulo: Paulus, 2010.

LÉVY, Pierre. O que é o virtual. São Paulo: Editora 34, 1996.

LÉVY, Pierre. Cibercultura. São Paulo: Editora 34, 1999.

LIMA, Marcio R. de. Projeto UCA e Plano CEIBAL como possibilidades de reconfiguração da prática pedagógica com as Tecnologias Digitais de Informação e Comunicação. 2015. Tese (Educação) - Universidade Federal de Minas Gerais, Belo Horizonte, 2015. Disponível em: https://repositorio.ufmg.br/handle/1843/BUBDA3BHSA. Acesso em: 14 abr. 2020.

LIMA, Marcio R. de; NASCIMENTO, Silvania S. do. Projeto UCA em Tiradentes: significações de duas professoras quanto às tecnologias digitais de informação e comunicação no contexto escolar. Educar em Revista, Curitiba, v. 32, n. 61, p. 223-240, set. 2016. Disponível em: https://revistas.ufpr.br/educar/article/view/46117/29235. Acesso em: 14 abr. 2019.

LÜDKE, Menga; ANDRÉ, Marli Eliza D. A. de. Pesquisa em educação: abordagens qualitativas. São Paulo: EPU, 1986. 
MASETTO, Marcos. Docência na universidade. Campinas: Papirus, 2012.

MEDEIROS, Pâmella de et al. Exergames como ferramenta de aquisição e desenvolvimento de habilidades e capacidades motoras: uma revisão sistemática. Revista Paulista de Pediatria, São Paulo, v. 35, n. 4, p. 464-471, 2017. Disponível em: http:// www.scielo.br/scielo.php?script=sci_arttext\&pid=S0103-05822017000400464\&lng=p t\&nrm=iso\&tlng=pt. Acesso em: 14 abr. 2020.

MENDES, Diego S. Luz, câmera, pesquisa-ação: a inserção da mídia-educação na formação contínua de professores de educação física. 2008. Mestrado (Educação Física) Universidade Federal de Santa Catarina, Florianópolis, 2008. Disponível em: https:// www.ufsj.edu.br/portal2-repositorio/File/dcefs/DISSERTACAO_Diego_Souza.pdf. Acesso em: 14 abr. 2019.

MENDES, Diego S. O estágio na licenciatura em educação física em perspectiva semiótica: (re)ver-se e (re)criar-se em imagens. 2016. Tese (Educação) - Universidade Estadual Paulista, Presidente Prudente, 2016. Disponível em: https://repositorio.unesp. br/bitstream/handle/11449/141476/mendes_ds_dr_prud.pdf?sequence=3\&isAllowed=y. Acesso em: 14 abr. 2019.

MENDES, Diego S.; BETTI, Mauro. O estágio em perspectiva semiótica: uma experiência mediada por imagens em um curso de licenciatura em educação física. Revista Brasileira de Educação, Rio de Janeiro, v. 2, p. 1-24, 2018. Disponível em: https://tinyurl.com/yx48o9d3. Acesso em: 14 abr. 2019.

MINAS GERAIS. Assembleia Legislativa de Minas Gerais. Lei $n^{\circ}$ 14.486/2002. Disciplina o uso de telefone celular em salas de aula, teatros, cinemas e igrejas. Belo Horizonte: Assembleia Legislativa, 09 dez. 2002. Disponível em: https://leisestaduais. com.br/mg/lei-ordinaria-n-14486-2002-minas-gerais-disciplina-o-uso-de-telefonecelular-em-salas-de-aula-teatros-cinemas-e-igrejas. Acesso em: 14 abr. 2020.

MERLEAU-PONTY Maurice. Phénoménologie de la Perception. Paris: Gallimard, 1997.

NUNES, Túlio V.; TOIGO, Adriana M.; FLORENTINO, José Augusto A. Exergames como ferramenta pedagógica na Educação Física escolar: uma revisão integrativa. Saúde e Desenvolvimento Humano, Canoas, v. 7, n. 2, p. 107-116, 2019. Disponível em: https:// revistas.unilasalle.edu.br/index.php/saude_desenvolvimento/article/view/5492. Acesso em: 14 abr. 2019.

SANDHOLTZ, Judith H.; RINGSTAFF, Cathy; DWYER, David. Ensinando com tecnologias: criando salas de aula centradas nos alunos. Porto Alegre: Artes Médicas, 1997.

SILVA, Mauro S.; BRACHT, Valter. Na pista de práticas e professores inovadores na Educação Física Escolar. Kinesis, Santa Maria, v. 1, p. 80-94, 2012. Disponível em: https://periodicos.ufsm.br/kinesis/article/view/5718. Acesso em: 14 abr. 2019.

SILVEIRA, Sérgio A. da. Tudo sobre tod@s: Redes digitais, privacidade e venda de dados pessoais. São Paulo: Sesc, 2017. 
STENHOUSE, Lawrence. La investigacion como base de la enseñanza. Madrid: Morata, 1993.

THIOLlENT, Michel. Metodologia da Pesquisa-ação. São Paulo: Cortez, 1996.

VAGHETTI, Cesar A. O.; VIEIRA, Karina L.; BOTELHO, Silvia S. da C. Cultura digital e Educação Física: problematizando a inserção de Exergames no currículo. Educação: teoria e prática, Pelotas, v. 26, n. 51, p. 3-18, 2016. Disponível em: https://wp.ufpel.edu. br/exergamelabbrazil/files/2018/07/EXG-teoria-e-pratica.pdf. Acesso em: 14 abr. 2019.

VAGHETTI, Cesar A. O. et al. Exergames na educação física: aproximações com o currículo escolar. Revista Didática Sistêmica, Rio Grande, RS, v. 20, n. 2, p. 79-92, 2018. Disponível em: https://periodicos.furg.br/redsis/article/view/8529/6054. Acesso em: 14 abr. 2019.

ZEICHNER, Kenneth. A Formação Reflexiva de Professores. Idéias e Práticas. Lisboa: EDUCA, 1993.

Texto recebido em 15/04/2019.

Texto aprovado em 15/04/2020. 